\title{
Agôn
}

Revue des arts de la scène

$7 \mid 2015$

La Distribution

\section{La Distribution}

Présentation du dossier

Barbara Métais-Chastanier, Anne Pellois et Julie Sermon

\section{CpenEdition}

Journals

Édition électronique

URL : http://journals.openedition.org/agon/4109

DOI : 10.4000/agon.4109

ISSN : 1961-8581

Éditeur

Association Agôn

Référence électronique

Barbara Métais-Chastanier, Anne Pellois et Julie Sermon, « La Distribution », Agôn [En ligne], 7 | 2015, mis en ligne le 21 mars 2014, consulté le 23 septembre 2020. URL : http://journals.openedition.org/ agon/4109; DOl : https://doi.org/10.4000/agon.4109

Ce document a été généré automatiquement le 23 septembre 2020.

Association Agôn et les auteurs des articles 


\title{
La Distribution
}

\author{
Présentation du dossier
}

Barbara Métais-Chastanier, Anne Pellois et Julie Sermon

1 Au début des années 1980, une enquête menée auprès de metteurs en scène pose la question des modalités, concrètes et symboliques, de la distribution. Mis à part cette enquête, exclusivement ancrée dans le champ théâtral, aucune étude systématique n'a été consacrée à la distribution dans les arts de la scène, alors même que celle-ci engage et articule des questionnements décisifs, au croisement de l'artistique, du politique et de l'économique.

2 L'apparente simplicité avec laquelle on définit la distribution - répartition entre les interprètes des rôles ou partitions d'une œuvre (théâtrale, chorégraphique, performative...) - ne doit en effet pas occulter les questions qui s'y embusquent et qui méritent d'être posées. En fonction de quels critères et de quels principes s'effectue cette opération de partage des rôles? Quel en est l'agent responsable? De quelle manière la distribution interagit-elle avec la création et/ou la réception d'une œuvre? En quoi détermine-t-elle des rapports de force ou de dépendance, politiques, symboliques et économiques, opérant aussi bien au sein des équipes de création (entre l'interprète et le/la maître/sse d'œuvre, entre les interprètes eux/elles-mêmes) que vis-à-vis des contextes dans lesquels les œuvres s'inscrivent?

Opération à la fois discrète (puisqu'elle a lieu dans les amonts de la création) et manifeste (elle s'impose dans toute sa visibilité au public), la distribution est ce geste qui conditionne l'existence et détermine l'œuvre de part en part: ses processus de création, sa dramaturgie, son économie, son inscription dans l'espace social et dans le champ des imaginaires collectifs, qu'elle contribue tour à tour à conforter, subvertir, déconstruire voire enrichir. Loin de n'être qu'un geste circonscrit au champ artistique, la distribution s'articule en effet toujours à un principe ordonnateur (consensuel ou dissensuel, majoritaire ou minoritaire, théorique ou pragmatique) qui la déborde et qu'il importe de mettre au jour, car c'est à travers lui que s'actualise la dimension idéologique et donc politique de ces constructions symboliques que sont les œuvres.

En décidant de consacrer son dossier $n^{\circ} 7$ (dirigé par Barbara Métais-Chastanier, Anne Pellois et Julie Sermon) à la question de la distribution, la revue Agôn a donc eu pour 
volonté d'attirer l'attention des chercheur.e.s et d'inviter les artistes à s'exprimer sur cet impensé des arts vivants, et pour ambition de tenter de circonscrire un champ dont l'acuité - et l'actualité - des problématiques qu'il soulève (qu'on pense, dernièrement, à Exhibit B de Brett Bailey ou à l'Othello blanc de Luc Bondy) n'ont finalement d'égal que la difficulté à les saisir dans leurs différentes dimensions et conséquences. Dans cette introduction, nous nous proposerons d'ouvrir à la complexité de questions qui ne manqueront pas de trouver des réponses (circonstanciées) et des prolongements (singuliers) dans la lecture des articles qui constituent ce dossier 